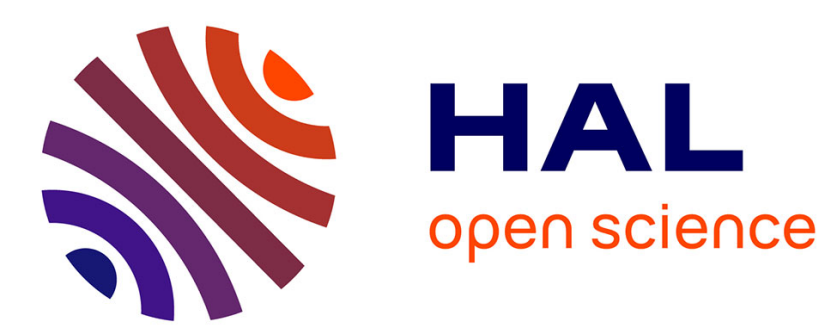

\title{
Fluorescence of Eu3+ ions in TiO2 optical planar waveguides fabricated by the sol-gel method
}

\author{
M. Bouazaoui, M. Bahtat, A. Bahtat, J. Mugnier
}

\section{To cite this version:}

M. Bouazaoui, M. Bahtat, A. Bahtat, J. Mugnier. Fluorescence of Eu3+ ions in TiO2 optical planar waveguides fabricated by the sol-gel method. Journal de Physique IV Proceedings, 1994, 04 (C4), pp.C4-341-C4-344. 10.1051/jp4:1994481 . jpa-00252744

\section{HAL Id: jpa-00252744 https://hal.science/jpa-00252744}

Submitted on 1 Jan 1994

HAL is a multi-disciplinary open access archive for the deposit and dissemination of scientific research documents, whether they are published or not. The documents may come from teaching and research institutions in France or abroad, or from public or private research centers.
L'archive ouverte pluridisciplinaire HAL, est destinée au dépôt et à la diffusion de documents scientifiques de niveau recherche, publiés ou non, émanant des établissements d'enseignement et de recherche français ou étrangers, des laboratoires publics ou privés. 


\title{
Fluorescence of $\mathrm{Eu}^{3+}$ ions in $\mathrm{TiO}_{2}$ optical planar waveguides fabricated by the sol-gel method
}

\author{
M. BOUAZAOUI, M. BAHTAT* ${ }^{*}$ A. BAHTAT ${ }^{* *}$ and J. MUGNIER**
}

Laboratoire de Spectroscopie Hertzienne, URA 249 du CNRS, Université Lille I, Bât. P5, 59655 Villeneuve d'Ascq, France

* Laboratoire du Traitement du Signal et Instrumentation, URA 842 du CNRS, Faculté des Sciences, 23 bd du Dr. P. Michelon, 42023 Saint-Etienne, France

** Laboratoire de Physico-Chimie des Matériaux Luminescents, URA 442 du CNRS, Université Lyon I, 43 Bd du 11 Novembre 1918, 69622 Villeurbanne, France

\begin{abstract}
In recent years, rare-earth-doped optical planar waveguides have attracted considerable attention owing to their potential use in the field of integrated optics. To this end, several processes have been employed to produce rare-earth-doped waveguides. Here, we report on the fluorescence of europium trivalent ions in $\mathrm{TiO}_{2}$ planar waveguides fabricated by using the sol-gel method and the dip-coating procedure. 2-mol $\% \mathrm{Eu}^{3+}: \mathrm{TiO}_{2}$ films were deposited on optically polished pyrex substrates. These films are $80 \mathrm{~nm}$ thick and their refractive index is ranging from 1.8 to 2.1 depending on the annealing temperature $\left(100^{\circ} \mathrm{C}-600^{\circ} \mathrm{C}\right)$. The fluorescence of $\mathrm{Eu}^{3+}$ ions was obtained by the excitation in the ${ }^{5} \mathrm{D}_{2}$ level with an Argon ion laser (wavelength $=465.8 \mathrm{~nm}$ ). At room tempurature, the fluorescence spectra were recorded for different annealing temperatures. A correlation was seen between the luminescence spectra and the structural evolution of the gel network. Indeed, it was observed that heat treatment increases the Stark splitting which partially removes the transitions J-degeneracy, indicating that $\mathrm{Eu}^{3+}$ ions occupy low-symmetry sites and are more embedded in the $\mathrm{TiO}_{2}$ gel (densification of the $\mathrm{TiO}_{2}$ gel). Furthermore, it was observed that increasing the annealing temperature entails a high frequency shift and a broadening of the ${ }^{5} \mathrm{D}_{0} \rightarrow{ }^{7} \mathrm{~F}_{0}$ transition, which shows that Eu ${ }^{3+}$ ions occupy more distorted sites. these observations are in good agreement with results obtained by waveguide Raman spectroscopy.
\end{abstract}

\section{Introduction}

Optical spectroscopy of the $\mathrm{Eu}^{3+}$ ions has been used recently to investigate the structures of silica gels ${ }^{[1,2]}$ and silica gels evolving toward glasses $[2,3]$. Campostrini et $\mathrm{al}^{[1]}$ have reported the study of the $\mathrm{Eu}^{3+}$ luminescence in sol-gel derived silica samples. Their work indicates that lifetimes, linewidths and Stark splittings of the $\mathrm{Eu}^{3+}$ transitions are an excellent probe for monitoring the densification process of the silica gels on heating.

The present work examines the $\mathrm{Eu}^{3+}$ fluorescence from $\mathrm{TiO}_{2}$ optical planar waveguides prepared by sol-gel process. The luminescence spectra and waveguide Raman spectroscopy were used to follow the structural evolution of the thin films waveguides. 


\section{Experimental}

The production of planar waveguiding $\mathrm{TiO}_{2}$ films with a dip-coating method has been described elsewhere[4]. Briefly, the starting solution was prepared using Titanium isopropoxide (Ti(O $\left.{ }^{i}\right)_{4}$ - Aldrich), iso-propanol (iPrOH-Merck) and acetic acid (AcOHProlabo) with a molar ratio $\mathrm{AcOH} / \mathrm{Ti}=6 . \mathrm{Eu}^{3+}$ ions were introduced by adding $\mathrm{Eu}\left(\mathrm{NO}_{3}\right)_{3}$ in a molar ratio $\mathrm{Eu}\left(\mathrm{NO}_{3}\right)_{3} / \mathrm{Ti}=2 \%$. The mixture obtained was diluted by methyl alcohol. Pyrex substrates $(75 \mathrm{~mm} \times 25 \mathrm{~mm}$ ) were careffully cleaned, then they were sinked into the solution and withdrawn from the bath at a rate of $40 \mathrm{~mm} \mathrm{mn}^{-1}$. Hence, the $2-\mathrm{mol}^{2} \mathrm{Eu}^{3+}: \mathrm{TiO}_{2}$ films obtained are first dried at $100^{\circ} \mathrm{C}$ and then heated at different temperatures $\left(300^{\circ} \mathrm{C}, 400^{\circ} \mathrm{C}\right.$ and $\left.600^{\circ} \mathrm{C}\right)$ in the oven under a constant flow of pure and dry oxygen.

The experimental set-up for waveguide Raman spectroscopy has been described in a previous article[5]. As shown in Fig.1, the incident beam delivred by a Krypton laser $(\lambda=647.1 \mathrm{~nm})$ is coupled into the thin film using either heavy glass or rutile prisms. Light scattered at $\pi / 2 \mathrm{rad}$ from the waveguide was analysed with a Jobin-Yvon model $U$ 1000 double monochromator followed by RCA AsGa photomultuplier tube. The signal was processed by an Ortec photon counting system and recorded under computer control. Europium fluorescence spectra were monitored with the same experimental set-up except for the Krypton laser which was replaced by an Argon ion laser. All the spectra were recorded at room temperature.

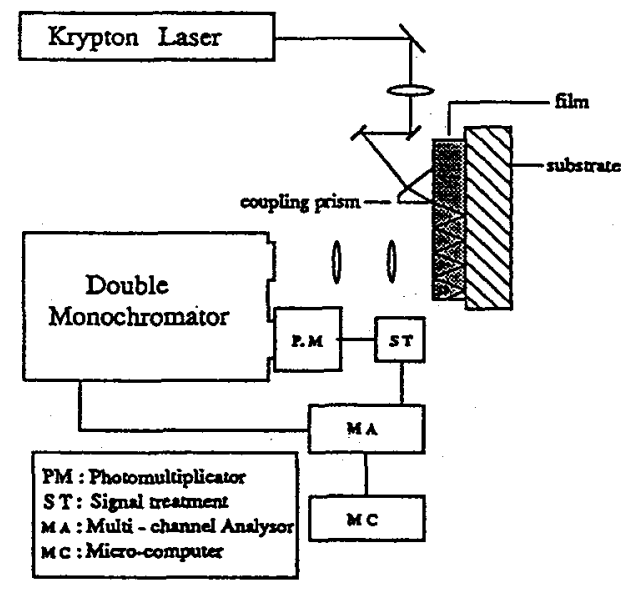

FIG.1. Schematic representation of waveguide Raman spectroscopy apparatus.

\section{Results:}

The emission spectra of 2-mol $\% \mathrm{Eu}^{3+}: \mathrm{TiO}_{2}$ thin films (thikness $=80 \mathrm{~nm}$ ) heated at various temperatures are shown in Fig.2. These spectra were obtained by the excitation in the ${ }^{7} \mathrm{~F}_{0} \rightarrow{ }^{5} \mathrm{D}_{2}$ line with an argon ion laser tuned at $\lambda=465.8 \mathrm{~nm}$. The luminescence was detected only from $5 \mathrm{D}_{0}$ state populated by non radiative relaxations from the excited state ${ }^{5} \mathrm{D}_{2}$. The ${ }^{5} \mathrm{D}_{0} \rightarrow{ }^{7} \mathrm{~F}_{0,1,2,3,4}$ transitions reported on figure 2 , shows that heat treatement of samples increases Stark splittings of transitions. This effect is clearly observed for the ${ }^{5} \mathrm{D}_{0} \rightarrow{ }^{7} \mathrm{~F}_{1}$ transition occuring at $16900 \mathrm{~cm}-1$. The full lifting 


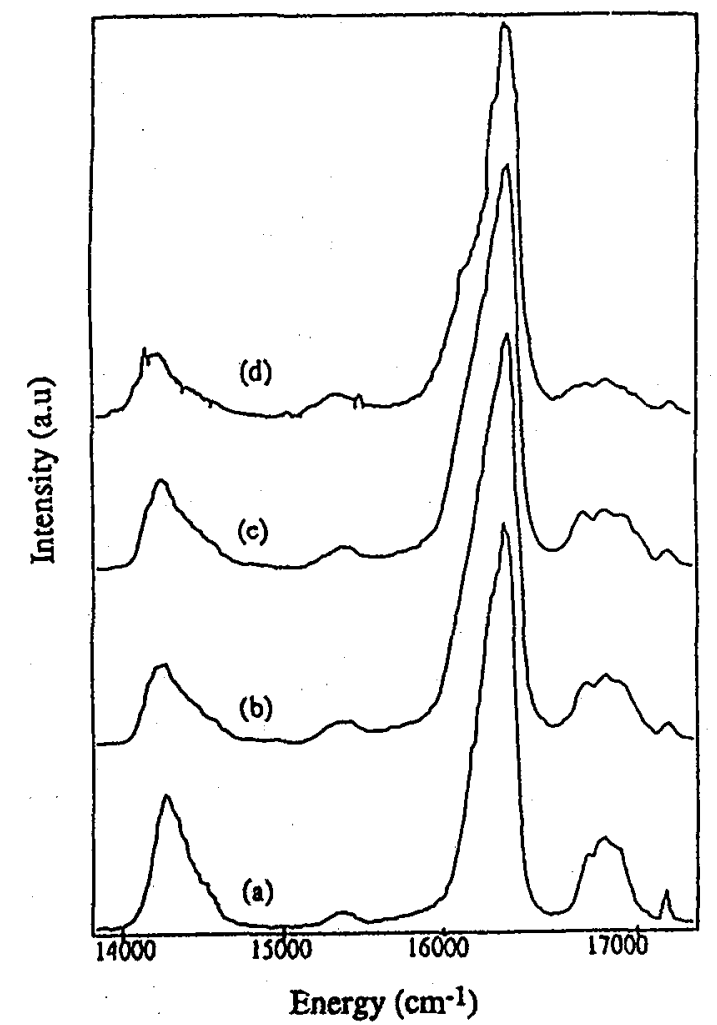

FIG.3. Luminescence spectra of the ${ }^{5} \mathrm{D}_{0} \rightarrow{ }^{7} \mathrm{~F}_{0}$ transition obtained by excitation in ${ }^{5} \mathrm{D}_{2}$ state for different heat treatments : (a) $100^{\circ} \mathrm{C}$, (b) $300^{\circ} \mathrm{C}$, (c) $400^{\circ} \mathrm{C}$, (d) $600^{\circ} \mathrm{C}$

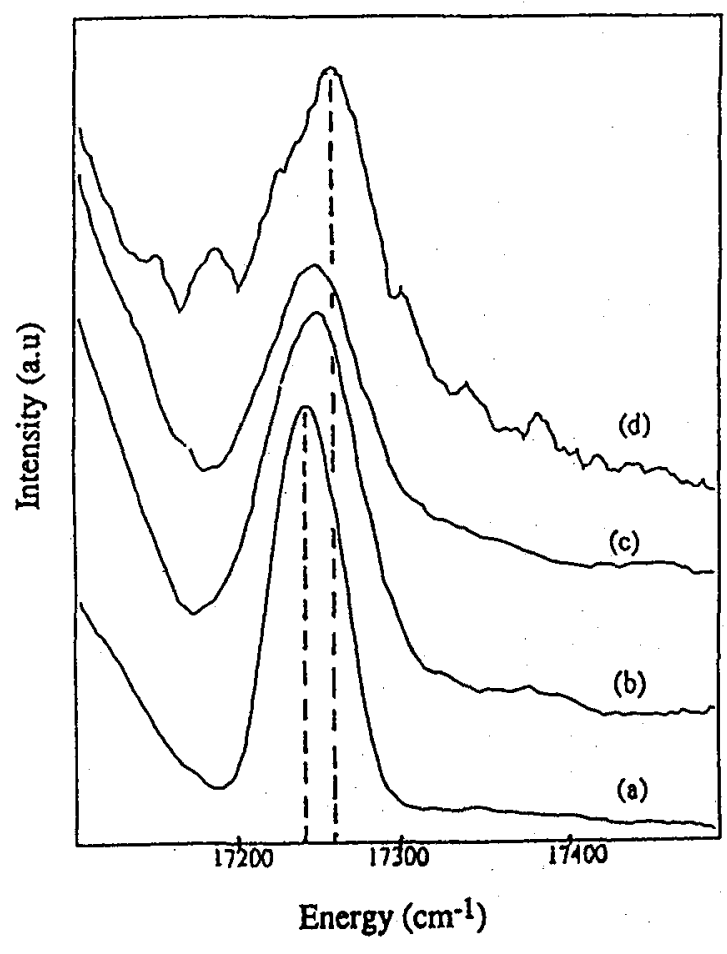

FIG.2. Luminescence spectra of 2-mol- $\% \mathrm{Eu}^{3+}: \mathrm{TiO}_{2}$ thin films waveguides obtained by excitation in $5 \mathrm{D}_{2}$ state for different heat treatments : (a) $100^{\circ} \mathrm{C}$, (b) $300^{\circ} \mathrm{C}$, (c) $400^{\circ} \mathrm{C}$, (d) $600^{\circ} \mathrm{C}$. 
degeneracy of the ${ }^{7} \mathrm{~F}_{1}$ multiplet corresponding to the triplet structure observed, indicates that the Eu ${ }^{3+}$ ions occupy low symmetry sites . Moreover, the increasing of Stark splittings on heating therefore of local crystal field indicates that $\mathrm{Eu}^{3+}$ ions are more embedded in the gel network. The ${ }^{5} \mathrm{D}_{0} \rightarrow{ }^{7} \mathrm{~F}_{2,3,4}$ transitions occuring respectively at 16200,15300 and $14200 \mathrm{~cm}^{-1}$, are more broadened at high annealing temperatures which is due to the strong local crystal field, but in this case the Stark components are not resolved. Figure 3 shows the ${ }^{5} \mathrm{D}_{0} \rightarrow{ }^{7} \mathrm{~F}_{0}$ transition. The mean energy of this transition increases with heat treatement and a slightly broadening on heating was observed. All these observations indicates that at high annealing temperatures, $\mathrm{Eu}^{3+}$ ions are more embedded in the gel network (gel densification) and occupy low symmetry sites .

Typical Raman spectra of $\mathrm{TiO}_{2}$ films annealed at various temperatures are shown in figure 4. The Raman spectrum of $2-\mathrm{mol}^{\%} \mathrm{Eu}^{3+}: \mathrm{TiO}_{2}$ thin film heated at $100^{\circ} \mathrm{C}$ exhibits a broad-bands characteristics of an amorphous structure. The same spectra was observed for an annealing temperature of $300^{\circ} \mathrm{C}$. At high annealing temperatures $\left(400^{\circ} \mathrm{C}\right.$ and $600^{\circ} \mathrm{C}$ ), resolved and narrow bands attributable to an anatase structure were observed at $144,197,399,516$ and $632 \mathrm{~cm}^{-1}$.

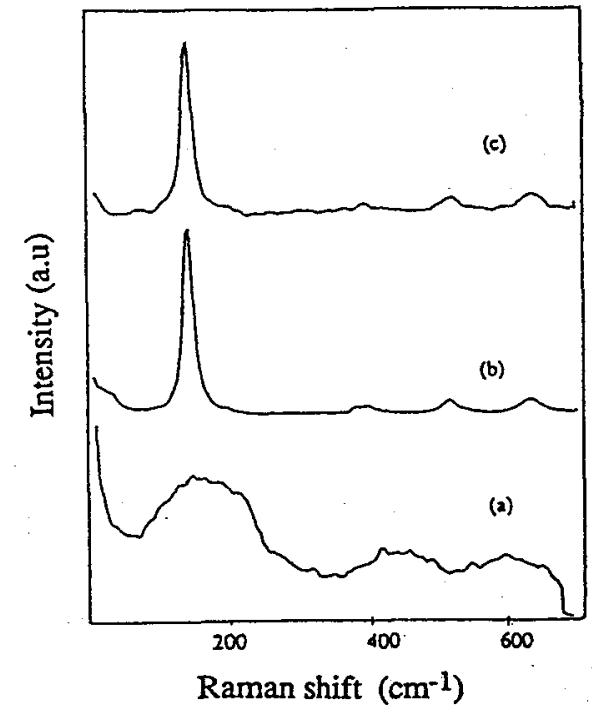

FIG.4. Raman spectra of 2 -mol $\% \mathrm{Eu}^{3+}: \mathrm{TiO}_{2}$ thin films waveguides annealed at : (a) $100^{\circ} \mathrm{C}$, (b) $400^{\circ} \mathrm{C}$, (d) $600^{\circ} \mathrm{C}$.

In conclusion, we have demonstrated that the densification of the gel network in 2$\mathrm{mol} \% \mathrm{Eu}^{3+}: \mathrm{TiO}_{2}$ thin films is monitored through changes in the emission spectra of $\mathrm{Eu}^{3+}$ ions. The waveguide Raman spectroscopy of these thin films confirms this correlation.

[1] R. Campostrini, G. Carturan, M. Ferrari, M.Montagna and O. Pilla. J. Mater. Res, Vol 7, N॰3, (1992) 745-753.

[2] M.J. Lochhead and K.L. Bray. ICL'93 Technical Digest, August 9-13, 1993 (University of connecticut).

[3] X. Fan, M. Wang and G.Xiong. Materials Science and Engineering, B21 (1993) 55-58.

[4] M. Bahtat, J. Mugnier, A. Bahtat, I.Serrughetti. Treizièmes journées Nationales d'Optique guidée, JNOG 93, 26-27 Mai (1993) 43/2.

[5] J. Mugnier, B. Varel, M. Bahtat, C.Bouvier and J.Serrughetti. J. Mat. Sci. Lett. 1992,11, p 875. 